\title{
Preface
}

\section{Cytopathology Comes of Age}

\author{
Zubair W. Baloch Prabodh K. Gupta \\ Department of Pathology and Laboratory Medicine, Hospital of the University of Pennsylvania, \\ Philadelphia, PA, USA
}

"Morphology bespeaks biologic behavior" has been the mantra of cytopathology since its beginning in the 1940s. Papanicolaou's original work and its numerous refinements by iconic figures such as Wied, Koss, Frost, Patten, Reagan, Hussain, Löwhagen, and Harald Zur Hausen among others has helped to establish the cytodiagnostics, the cytotechnologist, and most importantly cytopathologist as an essential part of the patient care team.

Today's cytopathologist is at the heart of patient management and is often called upon to provide a precise morphologic diagnosis which entails additional scrutiny of the nuclear and cytoplasmic features and the incorporation of ancillary procedures, including imaging, immunochemistry, FISH, flow cytometry, image analysis, and karyotyping.

With the advent of personalized (precision) medicine, during the past 20 years, there has been a renaissance in healthcare requiring tailored diagnosis and treatment. Genetic testing and molecular analyses of the tumors in light of cytomorphology is essential in this context. Therefore, being essential members of the patient management team, the cytopathology professionals are also required to have the necessary knowledge to serve as a link between tissue diagnosis and "molecular diagnosis" and "personalized medicine."

This issue of Acta Cytologica, comprising 17 papers written by well-known authors, contains a wealth of information that highlights the current trends regarding the use of ancillary techniques in the modern practice of cytopathology. This information highlights the wholesome and universal practice of cytopathology based on robust review of the literature and personal experiences.

The submission by Possati-Resende et al. [1] reports the implementation of HPV self-sampling in Barretos, São Paulo, Brazil. A thorough review of the role of immunohistochemistry in the cytologic diagnosis of pulmonary neoplasm is discussed by Metovic et al. [2]. The article by Jalaly et al. [3] sheds light on the current status of p16 testing of cytologic specimens in head and neck fineneedle aspiration (FNA) specimens. Thyroid fine-needle aspiration specimens are common in everyday practice of cytopathology. During the past decade the practice of thyroid cytopathology has been revolutionized by the use of ancillary molecular testing to improve risk stratification of thyroid FNA specimens. This important topic is discussed in detail by Nishino and Krane [4]. Recently, serous fluid cytology has dominated the international scene due to the assembling of a panel to develop a reporting framework. In this regard, the article by Yu et al. [5] is an important one and discusses the role of ancillary techniques in fluid cytology.

Other important contributions in this issue include the role of ancillary techniques in gynecologic cytopathology by Olivas et al. [6], diagnosing limited tissue sampling of hematopoietic lesions by Chadburn et al. [7], cytologic diagnosis of infectious agents in FNA specimens

\section{KARGER}

(c) 2019 S. Karger AG, Basel 
by Glaser and Montone [8], use of ancillary techniques in salivary gland FNA specimens by Point du Jour and Griffith [9], and the role of ancillary techniques in the cytologic diagnosis of solid lesions of the pancreas by Heymann and Siddiqui [10] and of cystic lesions of the pancreas by Jhala et al. [11].

In the current practice of "cytomolecular" diagnosis, it is important to be aware of the applicability of the various molecular tests and techniques, and most importantly their validation in cytology samples. In their separate submissions, Huang and Wei [12] and Sussman and Rosenbaum [13] discuss this topic in light of the available literature and their perspectives on the advantages and limitations of cytomolecular testing and validation.
The surgical pathology correlation is very important to the practice of cytopathology. Jenkins et al. [14] discuss the role of ancillary techniques in cervical and endocervical biopsy specimens as follow-up to Pap tests diagnosed as ASC-H or HSIL. The other reports in this issue highlighting the advances in the ancillary testing in cytopathology include submissions by Zhou and Moreira [15] on pulmonary cytopathology, Layfield [16] on biliary cytopathology specimens, and Allison and Van den Bussche [17] on urine cytopathology specimens.

In conclusion, we are honored to serve as guest editors of this special issue of Acta Cytologica, and are certain that you will enjoy reading the contributions by esteemed authors to highlight today's practice of cytopathology.

\section{References}

1 Possati-Resende JC, Vazquez FL, Pantano NP, Fregnani JH, Mauad EC, Longatto-Filho A. Implementation of a cervical cancer screening strategy using HPV self-sampling for women living in rural areas. Acta Cytol. 2019. doi: 10.1159/000493333.

2 Metovic J, Righi L, Delsedime L, Volante M, Papotti M. Role of immunocytochemistry in the cytological diagnosis of pulmonary tumors. Acta Cytol. 2019. doi: 10.1159/ 000496030.

3 Jalaly JB, Hosseini SM, Shafique K, Baloch ZW. Current status of p16 immunohistochemistry and HPV testing in fine-needle aspiration specimens of the head and neck. Acta Cytol. 2019. doi: 10.1159/000496158.

4 Nishino M, Krane JF. Role of ancillary techniques in thyroid cytology specimens. Acta Cytol. 2019. doi: 10.1159/000496502.

$5 \mathrm{Yu}$ GH, Glaser LJ, Gustafson KS. Role of ancillary techniques in fluid cytology. Acta Cytol. 2019. doi: 10.1159/000496568.

6 Olivas AD, Barroeta JE, Lastra RR. Role of ancillary techniques in gynecologic cytopathology specimens. Acta Cytol. 2019. doi: $10.1159 / 000496569$.
7 Chadburn A, Chen YH, Nayar R, Young A, Sumpter I, Lee C, et al. Limited tissue samples: hematopoietic lesions - three case examples of judicious use of limited material. Acta Cytol. 2019. doi: 10.1159/000496570.

8 Glaser LJ, Montone KT. A practical guide to the role of ancillary techniques in the diagnosis of infectious agents in fine-needle aspiration samples. Acta Cytol. 2019. doi: 10.1159/000497076.

9 Point du Jour K, Griffith CC. The role of ancillary techniques in salivary gland cytopathology specimens. Acta Cytol. 2019. doi: 10.1159/000497109.

10 Heymann JJ, Siddiqui MT. Ancillary techniques in cytologic specimens obtained from solid lesions of the pancreas: a review. Acta Cytol. 2019. doi: 10.1159/000497153.

11 Jhala N, Srimunta P, Jhala D. Role of ancillary testing in cytology specimens of pancreatic cystic neoplasms. Acta Cytol. 2019. doi: 10.1159/000502372.
12 Huang M, Wei S. Overview of molecular testing of cytology specimens. Acta Cytol. 2019. doi: $10.1159 / 000497187$.

13 Sussman R, Rosenbaum JN. Development and validation of molecular assays for limited tissue samples. Acta Cytol. 2019. doi: 10.1159/000499109.

14 Jenkins TM, Shojaei H, Song SJ, Schwartz LE. Role of ancillary techniques in cervical biopsy and endocervical curettage specimens as follow-up to Papanicolaou test results indicating a diagnosis of atypical squamous cells, cannot exclude high-grade squamous intraepithelial lesion, or high-grade squamous intraepithelial lesion. Acta Cytol. 2019. doi: 10.1159/000498888.

15 Zhou F, Moreira AL. The role of ancillary techniques in pulmonary cytopathology. Acta Cytol. 2019. doi: 10.1159/000498889.

16 Layfield L. Role of ancillary techniques in biliary cytopathology specimens. Acta Cytol. 2019. doi: 10.1159/000498976.

17 Allison DB, Van den Bussche CJ. A review of urine ancillary tests in the era of the Paris system. Acta Cytol.2019. doi: 10.1159/000499027. 